Quim. Nova, Vol. 36, No. 8, 1242-1247, 2013

\title{
EXPLORANDO AS PERCEPÇÕES DE PROFESSORES EM SERVIÇO SOBRE AS VISUALIZAÇÕES NO ENSINO DE QUÍMICA
}

\author{
Flávia Cristina Gomes Catunda de Vasconcelos* e Agnaldo Arroio \\ Departamento de Metodologia do Ensino e Educação Comparada, Faculdade de Educação, Universidade de São Paulo, 05508-900 \\ São Paulo - SP, Brasil
}

Recebido em 22/11/12; aceito em 19/3/13; disponível na web em 6/5/13

\begin{abstract}
EXPLORING TEACHERS' PERCEPTIONS ON VISUALIZATION RESOURCES IN CHEMISTRY TEACHING. Taking into account the requirements for the teaching of chemistry, several visualization resources (software, videos, animations, molecular models, among others) are available. These visual aids are used in order to enhance the understanding of chemical phenomena in the classroom. However, many teachers make scant use of these resources, limiting macroscopic understanding of chemical science. Thus, this article discusses chemistry teachers' views on several aspects such as using visual aids in teaching chemistry, a resource most widely used in classes on atomic models, isomerism and spatial geometry.
\end{abstract}

Keywords: representations; teachers of chemistry; views.

\section{INTRODUÇÃO}

Em meados da década de 90 era comum identificar pesquisas científicas que argumentavam a necessidade da utilização da experimentação no ensino de química. Ainda hoje, a realização de experimentos e aulas de laboratórios são utilizados com fins de ilustração e/ou investigação de conteúdos a serem explorados do macroscópico para a compreensão do micro. Entretanto, com o passar dos anos, se observa um aumento na criação de recursos visuais (softwares, vídeos, modelos moleculares, etc.) e sua utilização com 'manuais' quase irrefutáveis oriundos de pesquisas acadêmicas, que em sua maioria não atingem os professores da educação básica, devido ao distanciamento que ainda existe entre este nível de ensino e o ensino superior. O objetivo da inserção destes recursos em sala de aula se baseia na possibilidade de uma melhor compreensão da ciência Química por parte dos alunos, além de permitir que estes transitem melhor entre as três dimensões do conhecimento químico: macroscópica, submicroscópica e simbólica. ${ }^{1}$

Mesmo assim, percebe-se que o crescente número de recursos disponíveis para utilização em sala de aula é muito superior aos programas e cursos de formação em serviço para professores, com objetivos claros quanto aos pressupostos de usabilidade em sala de aula. ${ }^{2}$ Sem a formação adequada, ${ }^{2}$ muitos professores podem cometer equívocos comprometendo a compreensão de aspectos específicos que são transmitidos ao se utilizar estes recursos. Para que este processo aconteça de modo eficaz, é plausível a necessidade da realização de formações complementares para os professores em exercício por parte dos grupos de pesquisa em ensino de química, seja na educação básica ou no ensino superior.

Considerando que haja uma dificuldade na compreensão significativa da disposição de formas gráficas e representativas do conhecimento químico por parte dos professores, estes profissionais dominam interpretações equivocadas dos fenômenos em nível microscópico, que são refletidas na aprendizagem dos alunos em sala de aula. Este fato é devido à omissão de questões epistemológicas e ontológicas de tais representações nos cursos de formação inicial e continuada de professores. ${ }^{2}$ Pois,

\footnotetext{
*e-mail: flaviacrisgomes@hotmail.com
}

\begin{abstract}
“...estamos certos que é possível articular fundamentos epistemológicos da Química, como a especificidade da representação estrutural, com a organização das atividades de ensino na direção de superar visões eivadas pela memorização ou pelo experimento ingênuo. Para tanto é necessário focar a atenção na estruturação de atividades pelas quais as formações discursivas abriguem elementos representacionais das realidades macroscópicas e submicroscópicas, de modo que os estudantes dominem estes elementos para elaborar significados na fronteira destas realidades" (GIORDAN, 2008, p.81). ${ }^{3}$
\end{abstract}

Esta situação é mais preocupante quando os professores escolhem recursos sem fazer relação com a sua importância no contexto de sala de aula, sem a preocupação de como ocorrerá a compreensão daquele conteúdo ministrado e se este é suportado pelo recurso utilizado durante a aula. Destacando-se a necessidade de haver coerência entre o que é dito pelo professor, o recurso que este utiliza e as representações que o aluno faz durante o processo de aprendizagem.

No crescente número de pesquisas sobre recursos visuais (modelos) no ensino de química, percebe-se a dificuldade de alunos e professores em construírem e relacionarem estes modelos com habilidades de visualização espacial e analogias visuais. ${ }^{4}$

$\mathrm{Na}$ década de 90, ocorria a informática educativa com a inserção de computadores em sala de aula. Os softwares do tipo $2 \mathrm{D}$ e $3 \mathrm{D}$ permitiam a construção de modelos virtuais ${ }^{2}$ possibilitando que pesquisadores com foco no ensino médio e superior ${ }^{1,5-8}$ investigassem como estes recursos poderiam potencializar o processo de ensino e aprendizagem na disciplina Química. Assim, os alunos poderiam transitar entre os vários modos de representação, revelando dificuldades em aprender no sistema de transmissão de conhecimentos (ensino tradicional).

Outros estudos, ${ }^{9-12}$ reforçaram o princípio de que a visualização ocupa um papel central na aprendizagem, uma vez que os estudantes do ensino médio e superior apresentam dificuldades para interpretar fenômenos e transformações químicas em termos de modelos representacionais atualmente aceito. ${ }^{13}$

De qualquer perspectiva que se investigue, é fato que professores pesquisadores e profissionais de química necessitam ter o domínio de expressar os conhecimentos químicos pela articulação 
das três dimensões da realidade: macroscópica, submicroscópica e representacional. ${ }^{1,13-17}$ Dessa forma, reforça-se o paradigma de que a utilização de visualizações em situações estruturadas de ensino seja bastante produtiva para os estudantes se apropriarem das formas de pensamento químico. Ressaltando que, para que isto ocorra, os professores de Química, durante a sua formação, devem apropriar-se destas representações, sendo capazes de elaborar seus significados relacionados à realidade. ${ }^{3}$

Neste âmbito, diferentes definições para o termo 'visualização' têm sido utilizadas em pesquisas educacionais. De acordo com Gobert, ${ }^{18}$ pode-se ter três usos representacionais: visualização externa, visualização interna e ainda um terceiro como um tipo de habilidade espacial. Pode-se dizer, resumidamente, que a visualização externa refere-se tipicamente àquela utilizada para o aprendizado: gráficos, diagramas, modelos, simulações, animações, etc. Tendo diferentes características e, assim, diferentes recursos são necessários para os aprendizes atribuírem significados. Essa aproximação é similar ao que Gilbert, Reiner e Nakhleh ${ }^{19}$ referem-se à visualização como um substantivo. A visualização como uma representação interna é também usada para descrever construções (representações) mentais internas, que é individual e, sendo construída pelo indivíduo, de forma individual ou coletiva sendo necessária no processo de ensino e aprendizagem da ciência Química, uma vez que o professor e o estudante precisará ter um modelo mental de algo que está estudando, por exemplo, um modelo mental de átomo. ${ }^{20}$ Além disso, as representações internas podem ficar armazenadas na memória e a pessoa pode restaurá-la a fim de resolver problemas, criar inferências e tomar decisões. ${ }^{21}$ Entretanto, essa atribuição não é consensual; há muita divergência entre os psicólogos cognitivos sobre representações visuais internas em termos do seu formato representacional (formas proposicional/ semântico ou visual) e sua validade psicológica. ${ }^{18}$ Por último, visualização é também usada para descrever um tipo de habilidade espacial. ${ }^{18}$ Essas duas últimas atribuições (visualização interna e visualização como um tipo de habilidade espacial) são similares ao que Gilbert, Reiner e Nakhleh ${ }^{19}$ descrevem a visualização como um verbo, em que há uma ação mental na representação. ${ }^{22}$ Os exemplos dados como visualização externa foram analisados, sendo considerados possíveis exemplos de "visualizações" em química.

Considerando que as visualizações são importantes para a compreensão cognitiva dos fenômenos químicos, com suas potencialidades e limitações específicas de cada exemplo, ${ }^{23}$ e que o estímulo sensorial da visão quando explorado proporciona uma aprendizagem mais eficiente e interessante para os alunos. Assim, no ensino de Química, ao tentar desenvolver habilidades de representações mentais quando se utiliza as visualizações, é interessante os professores explicitarem que estas são representações do nível submiscroscópico, acontecendo neste nível as interações atômicas que muitas vezes apresentam mudanças ao nível macroscópico.

Neste sentido, o presente texto apresenta uma pesquisa realizada com professores de Química em exercício nos diferentes níveis de ensino, acerca do que estes compreendem sobre visualizações e sua experiência com recursos que podem ser exemplificados como visualizações. A proposta seria analisar quais as percepções que os professores apresentam diante do termo e o que isto representa para eles durante a sua atividade docente, buscando-se, também, verificar o quão relevante é para estes professores a sua utilização.

Para fins de análise também foi utilizada a Teoria da Codificação Dual (TCD) de Alan Paivio que prediz que a transmissão de informações ocorre de forma mais efetiva quando são utilizados os canais verbal e visual. ${ }^{24}$ Estes dois códigos organizam a informação em conhecimentos para a ação, armazenamento e recuperação posterior. ${ }^{2}$ Assim, a percepção tanto de textos quanto de imagens se dá por meio dos olhos; porém, após a entrada pelo sistema perceptivo, textos são transferidos para o canal verbal e imagens para o canal pictórico. Segundo esta teoria, existem pelo menos dois canais especializados no processo de informação. Um canal seria responsável pelo processamento da informação não verbal (objetos, eventos e imagens), outro canal processaria a informação verbal (texto impresso ou falado). Deste modo, compreende-se que informações armazenadas nos dois sistemas sejam mais facilmente lembradas do que aquelas armazenadas num único sistema.

\section{METODOLOGIA}

A pesquisa consistiu na criação de um questionário virtual construído na plataforma 'JotForm' (http://jotformz.com/ form/20825011470643) e sua aplicação foi realizada para professores de química. O questionário pode ser visualizado no material suplementar. Este tipo de questionário foi escolhido devido a sua potencialidade de divulgação, ampliando assim a coleta de dados para compor esta pesquisa, com professores de Química que atuam em todo o país, contendo questão abertas e fechadas que traçavam o perfil do entrevistado (sexo, idade, formação, experiência e tempo de ensino, disciplinas) e suas concepções sobre visualizações (conceito, exemplos, utilização destes recursos em suas aulas, e conteúdos que requerem o uso de visualizações). Os resultados apresentados no questionário elaborado nesta plataforma possibilitaram a análise da pesquisa em dados qualitativos e quantitativos.

A pesquisa foi divulgada através de correio eletrônico, com informações sobre os objetivos da pesquisa e da pesquisadora. Os recebimentos das respostas dos participantes eram salvos automaticamente na base de dados da plataforma JotForm e no e-mail cadastrado, incluindo informações de data e hora do registro das respostas dos professores. $\mathrm{O}$ uso desta plataforma foi considerado satisfatório aos processos de fechamento da coleta de informações, devido ao sistema disponibilizar mecanismos para geração de dados das perguntas fechadas e de armazenar as mesmas. Após o período de coleta, foi realizada uma análise exploratória dos dados segundo as referências citadas, ${ }^{1,24-27}$ as quais compõem vastas publicações na literatura, e com isto elaborada as categorias de resposta a partir dos dados apresentados pelos professores.

Foram considerados para análise todos os professores que apresentaram a experiência no ensino da disciplina de Química e afins. Com estes questionários, as repostas foram analisadas e elaboradas categorias de análise, além de se traçar um perfil dos professores que participaram desta pesquisa.

\section{RESULTADOS E DISCUSSÃO}

Ao todo, 137 professores responderam ao questionário, mas dois questionários foram desconsiderados pelo fato de os sujeitos não lecionarem a disciplina de Química. Foram analisados, no total, as respostas de 135 sujeitos que lecionam disciplinas de Química (ciência pura e/ou pedagógica), sendo estes de 20 estados brasileiros - AL(1); AM (3); BA (4); CE (1); ES (2), GO (8), MA (1), MT (3), MG (12), PA (5), PB (4), PR (9), PE (39), PI (2), RN (2), RJ (5), RS (3), SC (4), SP (23), SE (2) - e o Distrito Federal (2).

Dos professores que participaram da pesquisa, 74 eram do sexo feminino e 61 do sexo masculino. A figura 1 apresenta o nível de formação dos professores que participaram da pesquisa, ao analisar os cursos de formação, 106 informaram ter formação específica na área de Química (licenciatura/bacharel/mestrado e/ou doutorado), as demais formações citadas foram: Farmácia e Bioquímica (3); Engenharia Química (7); Biologia (7); Matemática (2); licenciatura em Ciência - habilitação em Química (6); Química industrial (1), Psicologia da educação (1), Educação científica e tecnológica (1) e Agroquímica (1). Na figura 2 observa-se a faixa etária que os 
profissionais estavam compreendidos, estes também informaram a área de atuação nos diferentes níveis de ensino: ensino fundamental (68), ensino médio (114), técnico (37) e superior (74). As respostas foram múltiplas, pois alguns professores atuavam em diferentes níveis.

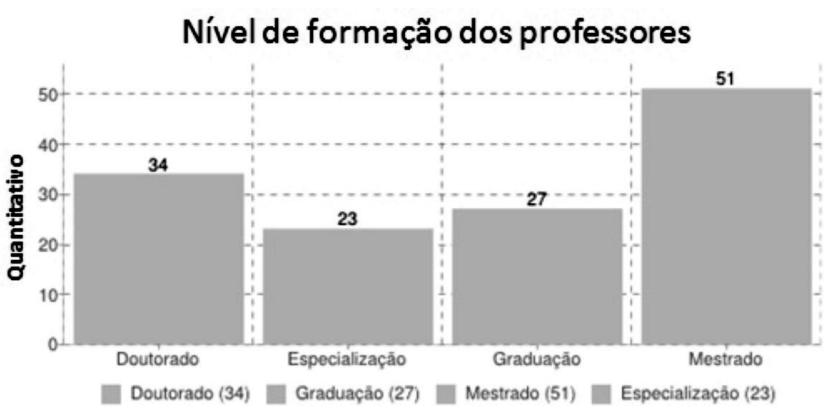

Figura 1. Nível de formação dos professores que participaram da pesquisa

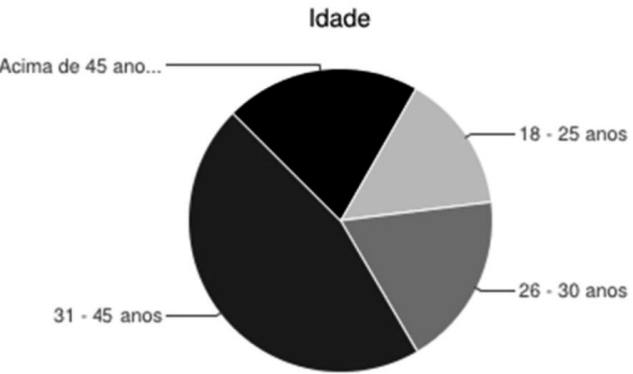

$18 \cdot 25 \operatorname{anos}(20) \square 26 \cdot 30 \operatorname{anos}(25)$ $31 \cdot 45$ anos $(62)$

Acima de 45 anos (28)

Figura 2. Gráfico que compreende a faixa etária dos professores que atuam como docentes na disciplina de química que participaram da pesquisa

Analisando o perfil de formação dos professores que participaram da pesquisa, percebeu-se que estes continham alguma formação que possibilitasse a sua atuação no ensino. Entretanto, esperava-se que estes profissionais conseguissem, durante o seu exercício docente, compreender a natureza da Ciência e suas inter-relações com a sociedade e a tecnologia. Mas, com os resultados apresentados, percebeu-se que a grande maioria não consegue compreender a ciência química relacionando com os três eixos do conhecimento.

O termo principal da pesquisa 'visualizações' foi analisado, ao se questionar: "Explique, de forma sucinta, o que você entende pelo termo "visualizações" no ensino de química?". Muitas respostas elucidavam, basicamente, os seguintes pontos: representar algo (39); utilizar recursos (45); enxergar/tonar visível/visualizar (14); método/ estratégia de ensino (19); entender algo (5) e, signos/significado/ modelos (10). Neste item, uma professora não respondeu, outro informou não entender o termo, e uma terceira fez a associação de três pontos: 'representar, 'signos/significado/modelos' e 'enxergar/ tornar visível', ao responder o seguinte:

"Modelos que permitam tornar "visível" certos conceitos relativos a fenômenos em nível microscópio. Representações”.

Esta informação permite interpretar que a professora faz a associação do termo 'visualizações' como uma representação do nível macroscópico do que não enxergamos (micro) relacionados a termos químicos. Todos os professores que usaram o termo representar como resposta fizeram uma associação com as palavras 'microscópico' e 'macroscópico'. Entretanto, apenas 12 professores inferiram sobre as interpretações internas que requer habilidades espaciais e alto nível de entendimento que esses modelos, quando utilizados em sala de aula, podem permitir a uma melhor aprendizagem. Estes usaram os termos 'imaginar; criar; abstrair'. É possível verificar estes dados ao analisar a resposta a seguir:

"A Química envolve a interpretação das mudanças na matéria, e trabalha-se em termos de mudanças imperceptíveis na dimensão submicroscópica. Utilizam-se, então, representações de forma simbólica e abstrata usando símbolos e fórmulas químicas, equações gráficos, imagens, etc. Penso então, que "visualizações" significaria o uso de todo tipo de representação não-verbal."

Nesta resposta, destaca-se também a percepção do professor para a importância da utilização de linguagens não verbais no ensino de Química, caracterizando que o mesmo compreende a importância da imaginação nas operações cognitivas, onde o conhecimento é potencializado quando se apresentam a informação de modo verbal e não-verbal da TCD. ${ }^{24}$ Outras respostas também apresentam a ideia do TCD e da linguagem não verbal:

"Entendo como sendo imaginar como algo que ocorre submicroscopicamente, criando uma imagem de algo que não vemos, mas acreditamos que ocorra desse modo."

"Competência representacional associada à necessidade da química trabalhar com representações que demandam habilidades de imaginação intuição e grafia de entidades com os quais trabalha"

"Entendo como o conjunto de exercícios mentais e recursos pictóricos através dos quais damos forma concreta a um conceito abstrato. Um modelo seria, de certa forma, uma tentativa de visualização"

Ao analisar o termo 'utilizar recursos', os professores citaram muitos exemplos figurativos, como se a visualização estivesse relacionada direta e exclusivamente com algum recurso didático, que facilitasse a compreensão dos fenômenos químicos, vejamos a seguir:

"São imagens que representam como deveriam ser os formatos de partículas, átomos ou moléculas e como se arranjam no espaço, se pudessem ser observadas, para um melhor entendimento dos seus comportamentos."

"Utiliza-se de ferramentas (imagens, vídeos, estruturas físicas) para passar ao aluno a realidade da química."

"É o uso de algum recurso imagético, seja figura, micrografia, representação didática de algum modelo teórico.”

Percebe-se nestas respostas a relação direta que o professor faz do termo 'visualização' com um recurso auxiliar no processo de aprendizagem do aluno, concebendo uma visualização externa dos fenômenos químicos. Entretanto, as visualizações deveriam ser exploradas pelos professores, como recursos que representam o microscópico, transitando assim nos três eixos do conhecimento químico. ${ }^{24-27}$ Apenas um professor, nesta classificação, destaca como um contexto não verbal, quando ele diz que

"Visualização é um termo amplo, mas no contexto de ensino de química, lembra mais esquemas, ilustrações, imagens, infográficos e outros recursos não textuais que representam um ou mais aspectos do tópico em estudo." 
Ou seja, além da utilização das informações verbais utilizadas em sala de aula, para uma melhor compreensão da ciência Química, utilizam-se também os recursos não verbais. ${ }^{24}$ Continuando a análise das respostas, 14 professores informaram que 'visualizações' são formas de se "ver", "enxergar" os fenômenos químicos, 'tornando visíveis', 'concretos', aquilo que não se vê, como se verifica nas respostas abaixo:

"São formas na qual enxergamos os fenômenos químicos"

"O que podemos analisar como forma concreta de ensino ligado as estruturas das moléculas em química."

"Realizar a concretização dos conceitos"

"O que se quer exemplificar de forma mais real. Algo que seja mais visível”

"Visualizações são formas visíveis de componentes químicos"

Estas concepções presentes no discurso do professor podem gerar nos alunos obstáculos epistemológicos. Especificamente, o obstáculo realista em que Bachelard ${ }^{25}$ descreve que, na tentativa de facilitar a compreensão, busca-se concretizar o abstrato através das imagens.

Em relação às respostas com as categorias de resposta 'método/ estratégia de ensino', os professores relacionavam com o processo de aprendizagem dos alunos, como se a 'visualização' estivesse intrínseca no método de ensino, permitindo que os alunos compreendessem melhor os conceitos da ciência Química, como se verifica abaixo:

"O grau de complexidade do conhecimento químico que meus alunos alcançassem numa análise de situação-problema (que pode ser de pesquisa ou do próprio cotidiano dele)".

"Maneira de perceber e abordar os conceitos de química"

"Entendo como estratégias de potencialização para compreensão de alguns conceitos químicos"

"É a forma de ensinar de uma maneira dinâmica e não somente a teoria."

"Tema importantíssimo no ensino de química, pois dará ao aluno suporte para que o mesmo possa entender a matéria."

"Conceber o ensino de química de forma clara e útil unindo o essencial, o prático e o científico na construção do conhecimento do aluno."

Na categoria de resposta 'entender algo', os professores escrevem o verbo "entender" com outros termos nas categorias anteriores, enfatizando que 'visualização' consiste em 'algo' que é utilizado para 'entender' a ciência Química. Por fim, na categoria 'signos/ significado/modelos', os professores respondem se referindo a signo/ significado, vejamos a seguir:

"Imagens que tem por trás algum modelo explicativo e tem a finalidade de mediar a significação de algum conceito. Diferente de símbolos."

"A visualização é a capacidade de transformar conceitos abstratos em imagens reais ou visíveis mentalmente. Mais além, envolve a capacidade de manipular essas imagens mentais, inclusive quando o estímulo visual é removido."
"Entendo de forma ampla como sendo todo sinal ou símbolo. Já que tudo que pode ser visto é por nós interpretado de alguma forma. A questão maior é da significação do sinall símbolo, isso só pode ser feito por meio do trabalho semiótico de significação. Penso que uma equação também é uma visualização, pois ela chega a ser tão carregada de significado que torna-se uma 'imagem' com sentido para quem a vê."

Segundo a teoria semiótica de Peirce, ${ }^{26}$ o conhecimento humano pode ser representado por uma tríade (signo, objeto e interpretante). Um signo é tudo aquilo que representa algo para alguém, como por exemplo, desenhos, símbolos, situações ou imagens. E, nesta ideia de tríade, o objeto, que é representado pelo signo, pode existir concretamente ou não. Neste sentido, quando o professor infere que "uma equação também é uma visualização [...] carregada de significado [...]." pode-se interpretar como o signo (equação) que representa o objeto (reação química). Para uma melhor compreensão destes signos no ensino de Química, o professor tem um papel fundamental, pois o mesmo mediará o conhecimento abstrato através da linguagem verbal e não-verbal, potencializando os signos, que possibilita que o estudante consiga compreender que este recurso é uma representação de um objeto que pode existir ou não.

A questão explorada em seguida apresentava imagens que podem se referenciar como 'visualizações', com a finalidade de questionar quais os professores considerariam como visualizações (Figura 3).
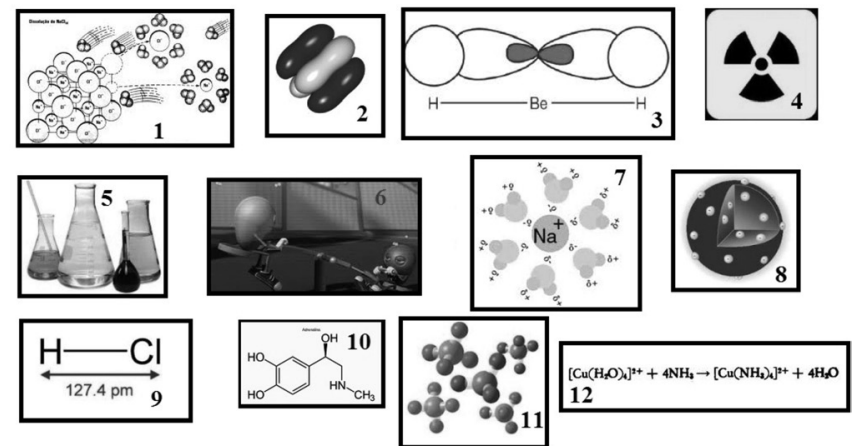

Figura 3. Imagens utilizadas no questionário da pesquisa. Definições: 1) Representação com ideia dinâmica da dissolução do $\mathrm{NaCl}$; 2) Representação atômica com nuvens eletrônicas; 3) Representação da ligação química do hidreto de berílio com a Teoria da Ligação de Valência; 4)Símbolo da radioatividade; 5) Vidrarias / soluções; 6) Vídeo com propriedades do átomo de oxigênio; 7) Representação da interação de íons sódio $(\mathrm{Na}+)$ com moléculas de água; 8) Representação do modelo atômico de Thomson; 9) Distância da ligação química do átomo de hidrogênio e cloro no ácido clorídrico em picômetros; 10) Representação estrutural da molécula de adrenalina; 11) Representação molecular (bola/vareta) para o metano; 12) Equação química representativa da formação do tetraaminocobre II

Todas essas imagens podem ser descritas como visualizações no ensino de Química, sendo não verbais construídas para representar o nível microscópico para compreensão dos fenômenos químicos. A figura 4 representa o quantitativo de professores que escolheram cada item.

Ao analisar a figura, percebe-se que a maioria dos professores considera como 'visualização' imagens (itens 1, 2, 3, 7, 8, 11, 12) que representam esferas (modelo atômico de Dalton). Mesmo com a evolução do modelo atômico, a representação deste ainda é utilizada nos livros didáticos e pelos próprios professores como se apresentassem o modelo "concreto" do átomo, considerando-os esferas maciças. Destacamos que, todos estes itens são visualizações, 


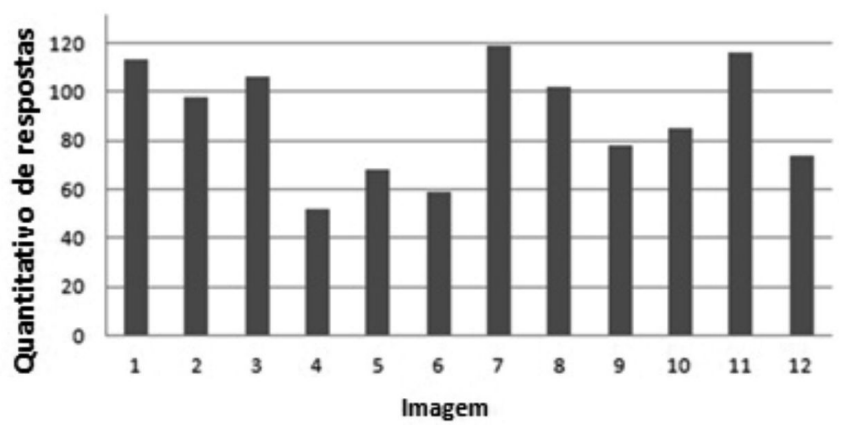

Figura 4. Relação do quantitativo de professores ao escolherem as imagens da figura 1

entretanto, se o professor não elucidar de que isto é uma representação, não o modelo real, o aluno poderá obter uma má interpretação do modelo levando a generalizações, e consequentemente a formas de raciocínios equivocados.

Um quantitativo menor de professores indicou o símbolo da radioatividade (item 4) como uma visualização, que é a imagem indica que este símbolo representa um material que emite radiação. O item 6 também foi pouco indicado pelos professores, o mesmo se refere a imagem de um vídeo, que é um dos recursos visuais mais utilizados no ensino de Química, junto a representação molecular seja através de imagens e/ou representações físicas de estruturas moleculares do tipo bola e vareta.

Em seguida, foram considerados para análise os assuntos em que o professor julga necessário o uso de visualizações nas aulas de química, justificando a sua escolha. O questionário apresentava 10 assuntos pré-selecionados, entretanto, era possível que os professores informassem outros (Figura 5).

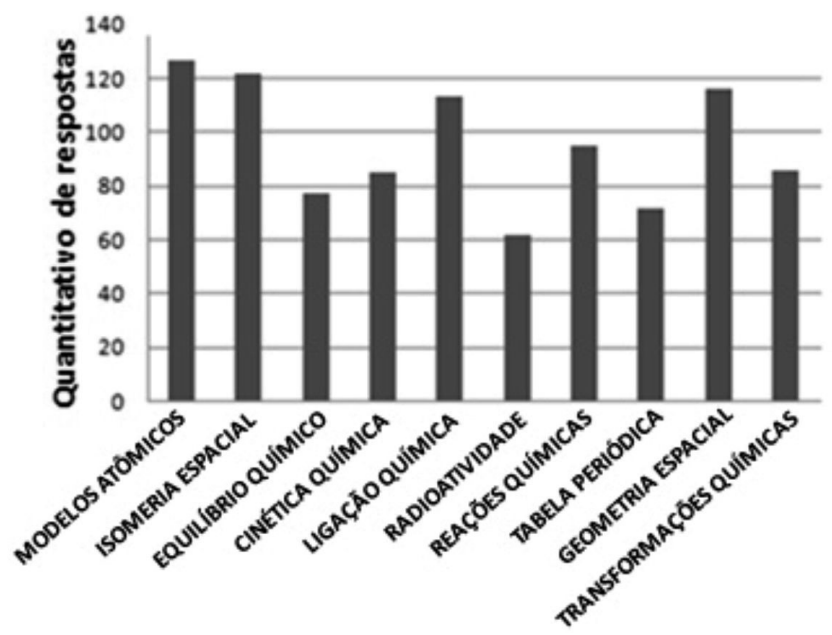

Figura 5. Quantitativo de assuntos indicados pelos professores para o uso de visualizações

A maioria dos professores escolheu modelos atômicos, isomeria espacial, ligação química e geometria espacial como assuntos que requeriam a utilização de visualizações. Este fato pode ser explicado devido à associação direta que se faz destes conteúdos com modelos, pois se ensina modelos atômicos, com representações visuais da estrutura da matéria estudada por vários cientistas no decorrer dos anos. E, isomeria espacial e geometria espacial, como se explora a disposição espacial dos átomos em uma molécula, inevitavelmente, faz-se necessário a utilização destes recursos. No caso das ligações químicas, os autores analisaram como representações da disposição dos elétrons nos átomos para se explicar as interações atômicas nos diferentes tipos de ligações químicas. Em um menor quantitativo, cita-se radioatividade e tabela periódica, a própria tabela periódica é um instrumento visual que apresenta a organização dos elementos químicos descobertos até então. Sendo, um instrumento de consulta, usado equivocadamente, por muitos professores de Química como meio decorativo para se aprender a nomenclatura dos elementos.

Os itens reações químicas e transformações químicas podem ser interpretadas como mesmo fenômeno, entretanto, para este questionário, o item transformações químicas estaria relacionada às explicações iniciais, que se detém apenas das representações macroscópicas e do cotidiano, que pode ser visto em livros didáticos, por exemplo. Este é ensinado em conjunto com as transformações físicas, nas séries iniciais que ensinam química. Logo, os dois itens foram considerados separadamente. As reações químicas geralmente são explicadas com representações simbólicas (equação química) e/ ou com experimentos que ilustram uma reação química. Com outros assuntos, os professores citaram: reações de compostos orgânicos (5); termoquímica (3); e, eletroquímica (3).

Como justificativa da escolha do recurso, em sua maioria, os professores informaram que utilizavam estes recursos para que os alunos 'compreendessem melhor aquilo que é 'abstrato', facilitando assim o seu processo de aprendizagem sobre os fenômenos químicos. Vejamos algumas respostas a seguir:

"Por exigir um bom nível de abstração, os assuntos selecionados podem ser melhor compreendidos através de modelos que representem o que pode ocorrer em nível microscópico de forma mais concreta."

"São os assuntos mais abstrato de compreensão por parte dos alunos"

"São assuntos que exigem um certo grau de abstração. Neste caso seria necessário o uso de modelos e visualizações."

"As imagens auxiliam na transposição do macroscópico para o microscópico. Auxiliam no processo de abstração, idealização, de conceitos e definições."

"Por tratar-se de conceitos abstratos ou transformações que ocorrem a nível submicroscópico.”

"Praticamente em todos os tópicos é necessário relacionar aspectos fenomenológicos, teóricos e representacionais.”

As respostas enfatizam a proposta de se utilizar visualizações como recursos auxiliares no processo de ensino e aprendizagem dos conteúdos de Química. Reforçamos ainda que estes precisam estar associados aos três níveis representacionais, como foi apresentado na última resposta.

No final do questionário, foi solicitado aos professores que transcrevessem em poucas palavras como são as suas aulas, relatando quais tipos de recursos esses professores utilizam. As mais variadas respostas foram apresentadas, demonstrando o quão diverso é o universo de metodologias de ensino nas aulas de Química nos diferentes níveis. De modo geral, percebe-se que a tentativa de se ministrar uma boa aula está geralmente relacionada à utilização de um experimento, data-show e vídeos, mas que em algumas situações isto não acontece devido à limitação do espaço escolar e restrição da carga horária direcionada para a disciplina de Química, sendo a utilização de recursos visuais um meio de estimular os alunos a prestarem mais atenção no conteúdo ministrado e para dinamizar a aula. ${ }^{27}$ 


\section{CONCLUSÕES}

A pesquisa demonstrou a diversidade das percepções dos professores sobre visualizações, e que estes utilizam para 'facilitar' o processo de ensino e aprendizagem em sala de aula, em diferentes níveis de ensino, e que isto independe de sua formação. A utilização do questionário virtual possibilitou coletar dados de diferentes estados do país, o que propôs uma diversificação nas respostas apresentadas sobre o que seriam 'visualizações'.

Por ser considerada uma ciência 'abstrata', mas com diversas aplicações no cotidiano, os professores devem realizar em sala de aula correlação direta das três dimensões da Química: macroscópica, submicroscópica e simbólica. Enfatizando que as imagens, animações e gráficos, por exemplo, são representações que explicam os fenômenos em nível microscópico. Investigando também quais representações os alunos estão fazendo destas explicações evitando distorções ou uma compreensão equivocada das explicações científicas referente à ciência Química.

Diante das respostas analisadas, os professores ainda precisam compreender mais adequadamente o que são 'visualizações', bem como o potencial de uso destes recursos em sala de aula, não se restringindo apenas a sua utilização de modo demonstrativo, evidenciando concepções ingênuas acerca do tema. ${ }^{2}$

Uma vez identificada a problemática na formação dos professores, esta implica na necessidade da inserção desta temática, nos cursos de formação inicial e continuada, visando uma formação mais contemporânea, principalmente para os professores de Química que estão em exercício por muitos anos.

Assim, percebe-se diante das respostas analisadas, que o modelo de ensino adotado pelas instituições de ensino superior, de modo geral, é falho no que tange a utilização das visualizações, pois a maioria dos professores não relacionou que estas representações visuais são representações do nível submicroscópico, assim gerando dificuldades nos alunos em relação à construção de modelos mentais. Ou seja, não aprenderam ou não compreendem bem que as ‘visualizações' são representações do conhecimento químico abordado em sala de aula.

Além disso, no ensino de Química, devem-se desenvolver práticas para a construção de modelos mentais com atividades experimentais ou manipulação de algo concreto, no nível macroscópico. Em seguida, é importante o professor trabalhar em nível submicroscópico, com o uso de imagens, simulações, vídeos ou modelos moleculares como forma de estímulo para os alunos raciocinarem no nível submicroscópico e elaborar os modelos mentais adequados ao sistema químico em estudo. O nível simbólico precisa ser empregado no ensino, pois este faz parte da Química, não devendo ser o único apresentado, uma vez que este, isoladamente, não auxilia na elaboração dos modelos mentais decorrentes da aprendizagem de conceitos químicos. ${ }^{23}$ Entretanto, os três eixos do conhecimento químico: macroscrópico, microscópico e o símbolo devem ser bem articulados para que haja uma aprendizagem eficaz nesta área.

\section{MATERIAL SUPLEMENTAR}

No material suplementar encontra-se o questionário utilizado para coleta de dados nesta pesquisa. Este está separado em duas partes, primeiramente com perguntas relacionadas ao perfil do professor e a segunda referente às 'visualizações'. Está disponível em http:// quimicanova.sbq.org.br, em arquivo pdf., com acesso livre.

\section{AGRADECIMENTOS}

À CAPES pela bolsa de doutorado e aos professores participantes da pesquisa.

\section{REFERÊNCIAS}

1. Johnstone, A. H.; J. Chem. Edu. 1993, 70, 701.

2. Ferreira, C.; Arroio, A.; What Do Pre-Service Teachers Think About Visualizations and it's Use in Chemistry Instruction? Em Proceedings of 14th International Organization for Science and Technology Education, Slovenia, 2010; Ferreira, C.; Arroio, A.; PEC 2009, 16, 48; Ferreira, C.; Arroio, A.; Rezende, D. B.; Quim. Nova 2011, 34, 1661; Arroio, A.; Honório, K.; PEC 2008, 9, 17; Arroio, A.; Journal Baltic Science Education 2012, 11, 2.

3. Giordan, M.; Computadores e Linguagens nas aulas de ciências, Ed. Unijuí: Ijuí, 2008.

4. Teruya, L. C.; Marson, G. A.; Anais da $34^{a}$ Reunião Anual da Sociedade Brasileira de Química, Florianópolis, Brasil, 2011; Teruya, L. C.; Marson, G. A.; Ferreira, C. R.; Arroio, A.; Quim. Nova 2013, 36, 561.

5. Driver, R.; Asoko, H.; Leach, J.; Mortimer, E.; Scott, P.; Educational Researcher 1994, 23 (7), 5.

6. Gabel, D. L.; J. Chem. Edu. 1999, 76, 548.

7. Hyde, R. T.; Sraw, P. N.; Jackson, D. E.; Woods, K.; J. Chem. Edu. 1995, 72, 699.

8. Ealy, J. B.; J. Chem. Educ. Tech. 1999, 8, 309.

9. Wu, H.; Krajcik, J. S.; Soloway, J.; J. Res. Sci. Teaching 2001, 38, 821.

10. Ferck, V.; Vrtacnik, M.; Blejec, A.; Girl, A.; Int. J. Sci. Edu. 2003, 25 , 1227.

11. Savec, V.; Vrtacnik, M.; Gilbert, J.; Evaluating the Educacional Value of Molecular Structure Representations; Em Visualization in Science Education; Gilbert, J.K., ed.; Springer: Dordrecht, 2007.

12. Kozma, R.; Russell, J.; Pupils Becoming Chemists: Developing Representational Competence; Gilbert, J. K., ed.; Springer: Dordrecht, 2007.

13. Garnett, P. J.; Garnett, P. J.; Hackling, M. W.; Studies in Science Education 1995, 25, 69.

14. Gabel, D. L.; Bunce, D. M.; Research on problem solving: chemistry; Em Handbook on research on Science Teaching and Learning; Gabel, D. L., ed.; Macmillan: New York, 1994, p. 301.

15. Gabel, D. L.; The complexity of chemistry and implications for teaching; Em International Handbook of Science Education; Fraser, B. J.; Tobin, K.G., eds.; Kluwer Academic Publishers: London, 1998, p. 233.

16. Bowen, C.W.; J. Chem. Edu. 1998, 75, 1172.

17. Ardac, D.; Akaygun, S.; J. Res. Sci. Teaching 2004, 41, 317.

18. Gobert, J. D.; Leveraging technology and cognitive theory on visualization to promote students science; Em Visualization in Science Education; Gilbert, J. K., eds.; Springer: Dordrecht, 2007.

19. Gilbert, J. K.; Reiner, M.; Nakhleh, M.; Introduction; Em Visualization: Theory and Practice in Science Education; Gilbert, J. K.; Reiner, M.; Nakhleh, M., eds.; Springer: Dordrecht, 2008.

20. Gilbert, J. K.; Em Visualization: A Metacognitive Skill in Science and Science Education; Gilbert, J. K., ed.; Springer: Dordrecht, 2007.

21. Rapp, D.; Kurby, C.; Em The 'Ins' and 'Outs' of Learning: Internal Representations and External Visualizations; Gilbert, J. K.; Reiner, M.; Nakhleh, M., eds.; Springer: Holland, 2008.

22. Locatelli, S.; Ferreira, C.; Arroio, A.; PEC 2010, 24, 75.

23. Stieff, M.; Bateman Jr., R. C.; Uttal, D. H.; Teaching and Learning with threedimensional representations; Em Visualization in Science Education; Gilbert, J. K., ed.; Springer: Holland, 2007, p. 93.

24. Paivio, A.; Mental representations: a dual-coding approach, Oxford Uni Press: New York, 1986.

25. Bachelard, G.; A formação do Espírito Científico, Contraponto: Rio de Janeiro, 1996.

26. Gois, J; Giordan, M.; Cadernos Temáticos da Química Nova na Escola 2007, 7, 34 .

27. Gibin, G. B.; Ferreira, L. H.; Quim. Nova 2010, 33, 1809. 


\section{EXPLORANDO AS PERCEPÇÕES DE PROFESSORES EM SERVIÇO SOBRE AS VISUALIZAÇÕES NO ENSINO}

\section{DE QUÍMICA}

Flávia Cristina Gomes Catunda de Vasconcelos* e Agnaldo Arroio

Departamento de Metodologia do Ensino e Educação Comparada, Faculdade de Educação, Universidade de São Paulo, 05508-900 São Paulo - SP, Brasil

Layout do questionário utilizado na coleta de dados desta pesquisa, disponível no link: http://jotformz.com/form/20825011470643.

\section{Pesquisa sobre Ensino de Química}

Esta pesquisa tem como objetivo traçar um perfil dos professores que lecionam a disciplina de Química, sobre o que se entende por visualizaçoes. Conto com sua colaboração.

\section{Perfil}

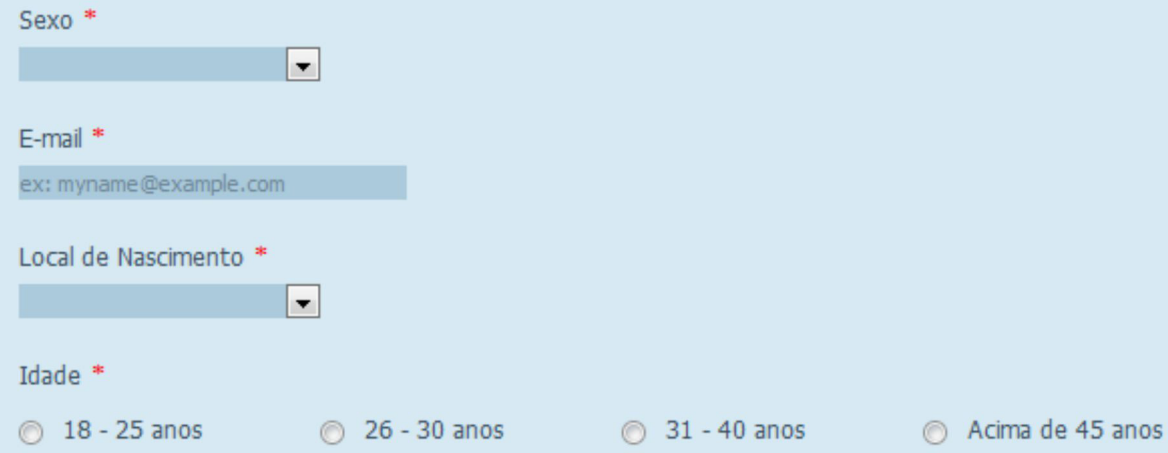

Formação*

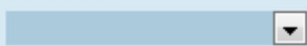

Curso *

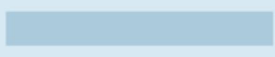

Insituição de ensino (Formação) *

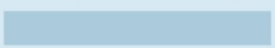

Ensina desde *

ex: 1990

Experiência profissional *

$\square$ Ens. fundamental $\square$ Ens. médio $\square$ Ens. técnico $\square$ Ens. superior

Disciplinas *

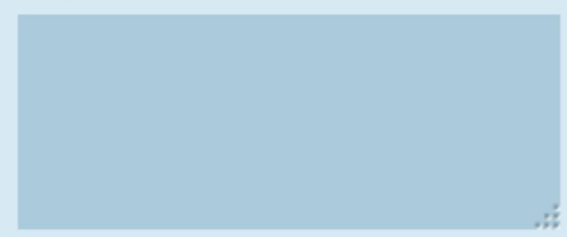

Estado que exerce a profissão *

Figura 1. Primeira parte do questionário com informações referente ao perfil do professor

*e-mail: flaviacrisgomes@hotmail.com 


\section{Visualizações}

Explique, de forma sucinta, o que você entende pelo termo "visualizações" no ensino de química? *

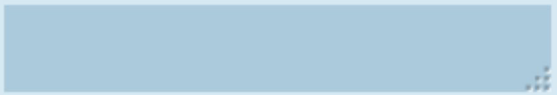

Analisando os itens enumerados abaixo, indique quais você considera como "visualizações" no ensino de química. *
1
$\square 2$
6
$\square 3$
$\square 4$
5
10
7
9
$\square 10$
11
12
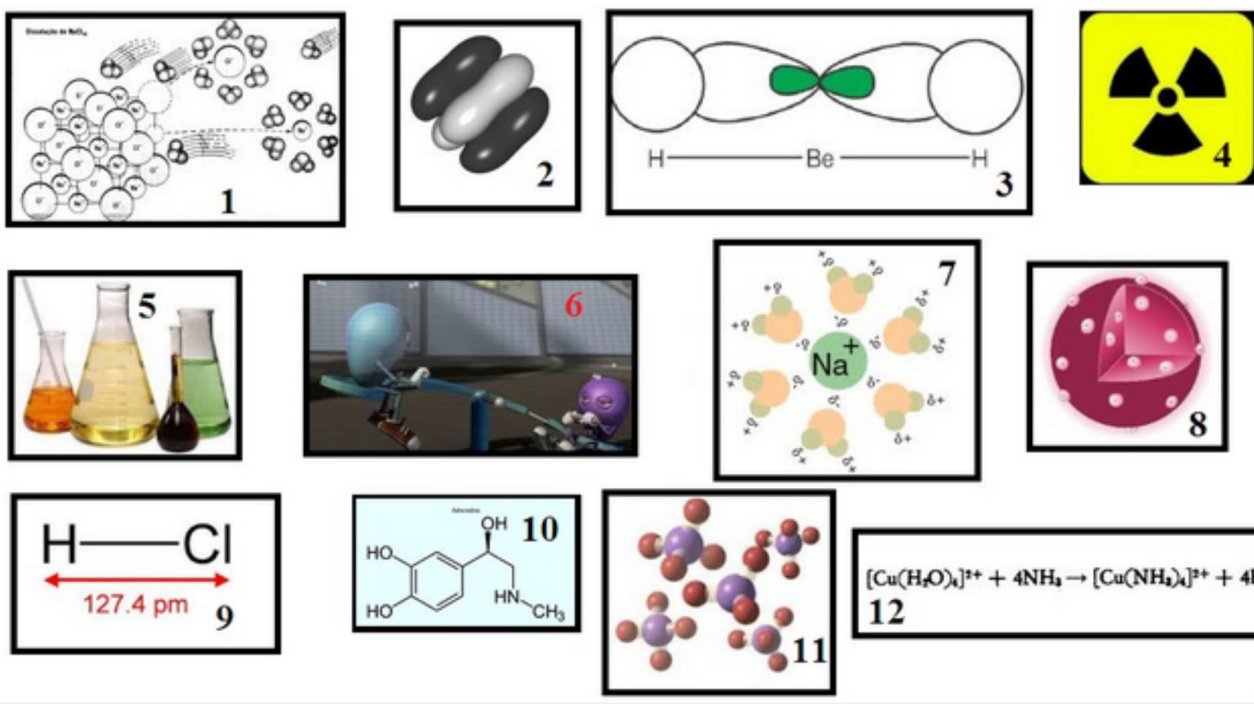

$\left[\mathrm{Cu}\left(\mathrm{H}_{2} \mathrm{O}\right)_{4}\right]^{3+}+4 \mathrm{NH}_{4} \rightarrow\left[\mathrm{Cu}\left(\mathrm{NH}_{3}\right)_{4}\right]^{3+}+4 \mathrm{H}_{5} \mathrm{O}$ 12

Utiliza algum dos itens indicados anteriormente nas suas aulas de química? Se sim, quais? Indique-os pelo número, dando nome aos selecionados *
Ex.: 1. Justificar o itemer o nome do item; 2. Justificar
o item; 3. Justificar o item ensino de química? *
Modelos Atômicos
Isomeria Espacial
$\square$ Equilibrio químico
Cinética Química
$\square$ Ligação Química
Radioatividade
Reações Químicas
П Transformação da Matéria
Tabela Periódica
Geometria Espacial

Dos itens abaixo, quais você considera necessário o uso de visualizações para uma melhor compreenssão do assunto, no

Caso tenha escolhido *Outros, indique-os abaixo.

Neste momento, justifique a escolha dos assuntos selecionados. *

Reflita, e transcreva em poucas palavras, como são suas aulas de química, relatando quais tipos de recursos você utiliza nelas. *

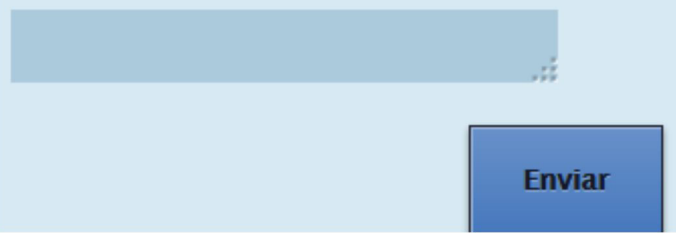

Figura 2. Segunda parte do questionário referente as 'visualizações' 